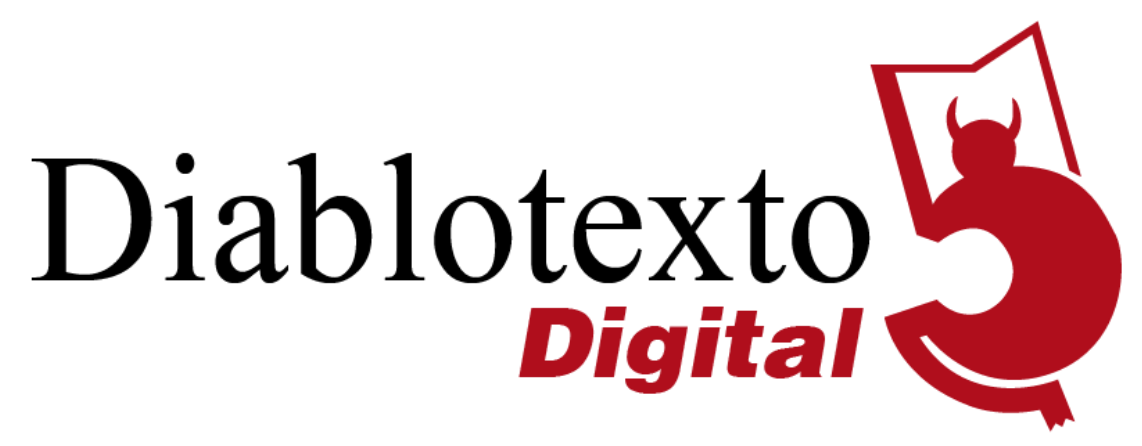

\title{
Desesperados intentos por decir el silencio: la ficción como instrumento de duelo
}

Desperate attempts to speak silence: fiction as an instrument for mourning

\author{
ANTHONY NUCKOLS \\ UNIVERSITAT DE VALĖNCIA
}

Resumen: Proponemos un análisis de El comprador de aniversarios (2002) de Adolfo García Ortega, publicado a comienzos del boom de la memoria en España, como una narrativa postraumática de duelo. Destacamos la novela entre otras contemporáneas que tratan la guerra civil española por su modo de acercarse al pasado, su uso de la ficción y por su temática. Trazamos los paralelismos que existen entre esta y Dora Bruder (1997) de Patrick Modiano, que pudo tener influencia en la de García Ortega. El resultado de esta narrativa de duelo es otro modo de entender nuestra relación en el presente con otro(s) pasado(s) violento(s).

Palabras clave: duelo, Holocausto, novela, memoria histórica, ficción

Abstract: We propose an analysis of El comprador de aniversarios (2002) by Adolfo García Ortega, published at the beginning of the memory boom in Spain, as a posttraumatic narrative of mourning. We single out the novel from among other contemporary novel son the Spanish Civil War for its way of approaching the past, its use of fiction and for its subject. We draw parallels that exist between the novel and Dora Bruder (1997) by Patrick Modiano, which could have influenced García Ortega's. The result of this mourning narrative is another way of understanding our relation in the present with (an)other violent past(s).

Key words: mourning, Holocaust, novel, historical memory, fiction 


\section{Introducción}

Reflexionar sobre la literatura en español en el siglo XXI, y específicamente en el caso de España, requiere necesariamente hacer referencia al llamado boom de memoria. A pesar del aumento en el número de publicaciones literarias, historiográficas o académicas ${ }^{1}$ en España a partir del cambio de siglo no podemos entender el interés social por la memoria, la Guerra Civil o la posguerra como prueba de que estos temas habían sido ignorados por la Historia y la literatura en décadas anteriores ${ }^{2}$. Sería un error también hablar de un fenómeno únicamente español, ya que el boom de la memoria forma parte de una misma preocupación mundial por temas relacionados con la memoria. En efecto, la globalización de estos discursos ha tenido una influencia tan abrumadora y amplia que es imposible desvincular el caso español de los debates y discursos en torno a la memoria provenientes de otros contextos como el Holocausto.

Es precisamente en ese momento del boom de la memoria internacional (y en España) que se publica El comprador de aniversarios (2002) de Adolfo García Ortega. A pesar de que el número de publicaciones nuevas y reediciones de obras sobre la Guerra Civil aumentaba con cada año que pasaba (Becerra Mayor: 421, 426), la novela de García Ortega vuelve la mirada no hacia el pasado español sino hacia el Holocausto. La influencia del Holocausto $u$ otros contextos (Argentina, Sudáfrica, etc.) se ve claramente a través de la importación e incorporación de un léxico específico e internacional (holocausto, genocidio, desparecido, etc.) procedente de diferentes discursos relacionados con la memoria, la justicia transicional y el trauma. En palabras de Gabriel Gatti, la importación de términos anteriormente asociados a otros contextos, como la Shoa o las dictaduras del Cono Sur, al caso español, ha hecho que "un viejo problema español se ve[a], de repente, incluido en una categoría universal (2012: 212) ${ }^{3}$. Empero los efectos del Holocausto convertido en memoria humana

\footnotetext{
1 En La guerra civil como moda literaria, David Becerra Mayor recoge un total de 181 novelas escritas y publicadas sobre la guerra civil española entre 1989 y 2011 (2015: 19).

2 Para investigaciones literarias anteriores al boom, véase el trabajo referencial de Maryse Bertrand de Muñoz o el de Raquel Maccicui (Martínez Rubio, 2015: 62).

${ }^{3}$ Gatti hace referencia al uso del término "desaparecidos" en el caso español (2012: 113). En cuanto al término holocausto, cabe destacar el libro de Monserrat Armengou i Martín y Ricard Bellis, titulado Les fosses del silenci: Hi ha un holocaust espanyol? (2004), basado en el
} 
universal no se limitan solo al ámbito teórico, historiográfico o de los derechos humanos, sino podemos encontrarlos también en el literario. Más allá de simplemente afirmar que ha habido (y habrá más) obras literarias españolas cuya temática gira en torno al Holocausto, lo que quiero hacer en el presente artículo es demostrar una influencia estética en la literatura española proveniente de la literatura europea sobre el Holocausto. En concreto me refiero a lo que en otro lugar he denominado narrativas postraumáticas de duelo4: esto es una narrativa postraumática, postmemorial, escrita en el presente que busca un modo de posicionarse respecto a las pérdidas del pasado que nos vienen heredadas.

Como ejemplo de esto, me centraré en la novela de Adolfo García Ortega y los paralelismos que se pueden dibujar con Dora Bruder (1997) de Patrick Modiano. Ambas tienen como su tema central el proceso de investigación y la reflexión acerca de dos jóvenes víctimas del Holocausto: en la novela de Modiano, una joven judía francesa deportada y exterminada; en la novela de García Ortega, un niño de tres años que muere en Auschwitz. En ambos casos, se trata de obras de autoficción en las que vemos al autor/narrador como primer motor de estos procesos de rescate del olvido. No obstante, veremos que es precisamente por la falta de datos sobre el pasado que los narradores tienen que recurrir a la inferencia y la suposición: este recurso a la ficción en el presente ante las incógnitas y el vacío constituye el modo de llevar a cabo el duelo.

En el caso de una catástrofe como el Holocausto la ficcionalización del pasado ha generado polémica y discusión sobre cómo tratar el pasado traumático en una obra literaria. Para mí, El comprador de aniversarios fuerza e incluso transgrede los límites de la ficción provenientes del debate sobre la representación del Holocausto, sobre todo si tenemos en cuenta la obra de García Ortega en relación con otras coetáneas, escritas sobre el pasado violento del siglo XX en España, la mayoría de las cuales tratan no el Holocausto sino la

programa homónimo emitido en TV3 en el año 2003. El programa se distribuyó en el mundo anglófono como The Spanish Holocaust. A esto habría que añadir también el libro de Paul Preston The Spanish Holocaust, publicado en el año 2011. Sobre la influencia del Holocausto en el movimiento memorialista en España, véase Baer, 2015.

${ }^{4}$ Véase Nuckols, 2016. 
Guerra Civil, la posguerra y la dictadura. Abordaré algunas de estas tensiones para luego detallar brevemente qué entiendo por narrativas postraumáticas de duelo; en cuanto a la novela de Modiano, me limitaré a exponer los motivos por los que la podemos considerar como tal; su estética y modo de retratar la posición de un narrador que pretende indagar en el pasado han sido, a mi entender, influyentes para la obra de García Ortega. Pese a los elementos de investigación historiográfica, que son integrales a ambas obras, sostengo que su finalidad no es tanto arrojar luz sobre aspectos desconocidos o ignorados del pasado, sino más bien construir un testimonio de la imposibilidad de saber y de recuperar el pasado: una reflexión sobre nuestra posición en un presente alejado de dicha tragedia. Ante la imposibilidad de conocer y nombrar la ausencia, el recurso a la ficción deviene un modo de responder ante el vacío, de conmemorar la ausencia producida por la catástrofe.

\section{Historia y ficción}

Entre las obras literarias producidas a partir del cambio de siglo en España sobre la Guerra Civil, Hans Lauge Hansen describe una "mímesis de la memoria cultural" (2012: 89): una literatura influenciada por el ambiente socio-político (medidas legislativas y judiciales, debates en la esfera pública) y el movimiento memorialista (grupos como la Asociación para la Recuperación de la Memoria Histórica). El resultado es un grupo de autores, la mayoría nacida a mediados o a finales de la dictadura franquista, que entienden la creación literaria como un modo de participar en esa recuperación de la memoria histórica, asumiendo, como sugiere Sebastiaan Faber, un papel activo en el espacio público sobre los debates en torno a la Segunda República, el Franquismo e incluso la Transición (2012: 130).

Para estos autores, la literatura es una herramienta para recuperar los restos olvidados o ignorados de la historia, un proceso cuya comparación con las exhumaciones es innegable. La obra literaria busca arrojar luz sobre una figura, un acontecimiento o episodio olvidado, ignorado o perdido de la Historia 
para así introducirlo dentro de la memoria colectiva actual ${ }^{5}$. Ante una literatura cuya función consiste en parte en rescatar hechos, hay que plantear la pregunta de si los escritores de ficción han de adscribirse (o someterse) a las mismas normas que los historiadores: por mucha investigación histórica que se le dote a la obra literaria, muchos de estos autores "continue to reserve the right to make things up" (Faber 2012: 130). José Martínez Rubio aborda esta pregunta sobre la delicada relación entre ficción e Historia, verdad y mentira en las novelas de investigación y autoficción: sobre el porqué de tanto recurso periodístico en estas obras, se puede atribuir "esta profusión documental a una voluntad de representación anti-ficcional, a un intento de distanciamiento con respecto de la ficción o de la fabulación para aproximarse a lo real" (2015: 113). En estas ficciones dotadas de elementos "reales", la verdad objetiva se queda ambigua: la verdad "no gira solamente en torno a la forma, a su ser, sino que alcanza su estatus de 'verdad' cuando es reconocida como tal [...] por las partes integrantes de un proceso de comunicación", que serían en este caso entre autor y lector (ibíd.: 97). A partir de esa mezcla de verdad y ficción han surgido críticas, como en el caso de Soldados de Salamina de Javier Cercas: "its clever mix of fact and fiction purposely mystifies historical truth, precisely at a moment when the truth what Spain is trying to retrieve" (Faber 2012: 130) ${ }^{6}$. Martínez Rubio nos insta a considerar esta ambigüedad que surge de la tensión entre verdad histórica y creación ficcional como una

tercera vía, como alternativa controlada a la realidad, por un lado, y a la ficción, por otro.[...] La posibilidad de entender la verdad como algo relativo, así como la realidad como algo inaprensible e inefable no hace sino abrir posibilidades a una sana complejidad. No supone nunca renunciar a la verdad, sino reforzar el compromiso con ella (2015: 119-120).

\footnotetext{
${ }^{5}$ Para una lista de obras con estas características, véase Nuckols, 2016.

${ }^{6} \mathrm{O}$, cuando no críticas, ha dado lugar a suposiciones erróneas sobre elementos ficticios como el caso del personaje de la escritora Dolores Serma en Mala gente que camina de Benjamín Prado: "me ha hecho ilusión que muchos periodistas me confesaran que antes de ir a entrevistarme habían mirado en Google qué salía al teclear el nombre de Dolores Serma, incluso uno me preguntó si pensaba hacer una edición crítica de su supuesta novela Óxido" (El País 2006).
} 
La fusión de ficción e Historia en las producciones literarias o cinematográficas que tratan el tema del Holocausto ha producido un sinfín de debates teóricos sobre el modo "correcto" de representar la catástrofe ${ }^{7}$. Muchas de las teorías sobre cómo contar o narrar el Holocausto, sean testimonios directos o no, parten de una suposición a priori de que se trata de un acontecimiento irrepresentable: desde el famoso dictum de Adorno al carácter "no conocible" de lo que Dori Laub llama "un acontecimiento sin testigos", pasando por la comparación de Lyotard del Holocausto con un terremoto que no solo destruyó vidas, ciudades, sino también todas las herramientas necesarias para medir los daños. Sin embargo han sido muchos los supervivientes que han compartido sus experiencias en forma del testimonio escrito a pesar de la dificultad y la imposibilidad que puede suponer para autores supervivientes como Delbo, Wiesel, Levi y Semprún?

These writers and survivors, and many others, believe that it is not possible for those who did not survive to understand, in a truthful way, the events of the Holocaust. Language is not enough. [...] there is an insurmountable difficulty in understanding the existential truth of the events using "free words". (Eaglestone, 2004: 18)

Para los que vivimos en el mundo post-Holocausto, estos testimonios suponen cierta contradicción, ya que como lectores estamos atrapados entre la imposibilidad de entender del todo la experiencia del lager y una literatura que, a la vez, pide ser consumida (ibíd.: 19).

Si la identificación con la víctima por parte del lector de un testimonio supone un deber contradictorio ${ }^{10}$, ¿qué ocurre cuando se trata de una obra de ficción? En una reseña de Antonio Muñoz Molina sobre El comprador de

\footnotetext{
${ }^{7}$ Existen una serie de "tabúes discursivos" y una "ética representacional" que no se han creado en España para las representaciones sobre la Guerra Civil (Faber, 2012: 131).

${ }^{8}$ Giorgio Agamben matiza esta observación de Laub afirmando que la Shoá se trata de un acontecimiento sin testigos en el doble sentido "de que sobre ella es imposible dar testimonio, tanto desde el interior -porque no se puede testimoniar desde el interior de la muerte, no hay voz para la extinción de la voz- como desde el exterior, porque el outsider queda excluido por definición del acontecimiento" (2000: 35).

${ }^{9}$ Elie Wiesel afirmaba, "Our generation invented a new literature, that of testimony" (en Felman y Laub 1992: 5-6).

${ }_{10}$ Eaglestone escribe que "for Wiesel, Delbo, and others, it is both that identification cannot happen in any meaningful way and that is should not happen" (22).
} 
aniversarios, el autor insiste en distinguir entre las obras escritas por supervivientes que "a pesar de escribir obra ficticia, sí vivieron el internamiento en campos y el Holocausto en directo", y escritores judíos como Saul Bellow o Isaac Bashevis Singer (2003: 76). Para estos escritores de ficción no supervivientes, sus personajes no pueden ser testigos directos y solo pueden llegar a conocer los horrores del Holocausto a través de otros testigos directos, igual que nosotros. En su análisis de varias obras de ficción escritas en inglés y, en su mayoría, por autores no judíos, Sue Vice afirma que las ficciones sobre el Holocausto son controvertidas porque parecen provocar repulsión y críticas laudatorias por partes iguales. Sobre la cuestión de quién tiene el derecho de escribir sobre el Holocausto, Vice escribe que aquellos autores de ficción que puedan demostrar alguna conexión (familiar o cultural) con lo que escriben parecen contar con más autoridad, debido a la incapacidad de desvincular la obra ficcional del género del testimonio (2000: 4).

Los casos de los falsos testimonios como el de Binjamin Wilkomirski parecen poner a prueba no solo lo importante que es esta cuestión de autoridad pero también lo fina y delicada que es la línea entre ficción e Historia/mentira y verdad. En 1995 Wilkomirski publica Fragmentos: Memorias de una niñez en tiempos de guerra (1939-1945). Unos años después, un periodista suizo descubre que se trata de un fraude: el autor no se llama Wilkomirski (sino Dössekker), no había nacido en Latvia, ni había estado preso en Majdanek ni Auschwitz y que ni siquiera es judío. El autor desde entonces ha sido desacreditado y el libro no se ha vuelto a publicar, pero a pesar de la mentira lamentable, hay que reconocer que si el autor hubiese publicado las memorias como ficción desde el principio, el caso no habría habido escándalo ${ }^{11}$.

Las controversias producidas en torno a la verdad y la ficción no se limitan solo a los casos de testimonios falsos sino también a un "uso correcto" de la ficción en la literatura. En el llamado "Debate Sefarad", ocurrido entre el hispanista y escritor austriaco Erich Hackl y Antonio Muñoz Molina y publicado

\footnotetext{
11 Varios críticos eran firmes en su defensa del texto por su calidad literaria, a pesar de la controversia: "Susan Suleiman described Fragments as a "work of literary art, powerful in its effect"' y Lawrence Langer "regarded the book to be 'a very compelling work of literature"” (en Whitehead, 2004: 31).
} 
por la revista Lateral12, Hackl acusa a Muñoz Molina de inventar y cambiar innecesaria y descuidadamente datos sobre algunos de las figuras históricas que aparecen en su novela Sefarad, cosa que según Hackl sería un ejemplo del "concepto falsificador de la realidad que Tzevtan Todorov había llamado infracción al orden: cambiar hechos, sentimientos, experiencias según las necesidades narrativas" (2001a). El escritor austriaco cierra su segunda intervención explicando que él había tomado al protagonista de Sefarad, Isaac Salama, como una persona real, siguiendo lo que la escritora alemana Christa Wolf "llamó el tabú de Auschwitz como objeto de la literatura escrita por generaciones posteriores: el precepto de no novelar la historia del Holocausto con testimonios de los sobrevivientes" (2001b).

\section{Narrativas postraumáticas de duelo}

Si las obras de investigación buscan distanciarse de la ficción, las narrativas postraumáticas de duelo utilizan la ficción (la suposición, lo que posiblemente pudo haber ocurrido) como un modo de participar de un duelo colectivo por las pérdidas de las que estamos temporal y espacialmente alejados en el presente.

Según las primeras teorías expuestas en Duelo y melancolía (1917), Freud hacía una distinción entre estos dos procesos. El duelo se da cuando una persona se percata de la pérdida definitiva del objeto de deseo: en la mayoría de los casos, un ser querido, pero también una idea más abstracta como la pérdida de libertades, derechos, etc. El duelo llega a su fin cuando el sujeto es capaz de encontrar un sustituto y reinvertir su deseo en él. Por otra parte, la melancolía se da cuando la persona es incapaz de desprenderse del todo del objeto perdido, dando paso a un estado patológico y violento en el que la substitución es imposible. Aunque más tarde Freud matizaría esta distinción en El yo y el ello, el binario freudiano del duelo versus la melancolía sigue siendo la base para la mayoría de teorías del duelo en la actualidad, según las cuales el éxito del proceso de duelo sano se reduce al reemplazo del objeto perdido

\footnotetext{
12 Las tres intervenciones se publicaron en sucesivos números de la revista Lateral (descontinuada) a lo largo del año 2001.
} 
En los estudios culturales, y literarios en particular, ha habido un rechazo general hacia el llamado paradigma consolatorio (Clewell, 2009), el cual se ha tachado de conservador, exclusivista y conducente a la amnesia, donde la sustitución se ha descrito, en el mejor de los casos, como un retorno al status quo, regido por un modus operandi capitalista donde el objeto original se ve como algo desechable (Brisley, 2013); en el peor de ellos, se ha teorizado como un acto de matar que condena al objeto perdido a una muerte irreversible (Eng y Han, 2003: 365). Según esta "despatologización" de la melancolía, el proceso melancólico de aferrarse al objeto perdido y de rechazar la consolación y la sustitución se ha reivindicado y teorizado como un proceso con mucho potencial político y creativo.

Aunque entiendo el paradigma consolatorio como problemático, ética y políticamente sospechoso, no veo la melancolía original de Freud como modelo productivo. Asimismo, las preocupaciones por la consolación y la pregunta de qué implica un proceso de duelo son particularmente relevantes (y se complican aún más) en el caso que aquí nos concierne: en el presente postraumático y postmemorial, ¿cómo pueden las pérdidas de generaciones anteriores, la cuales no son nuestras directamente, ser elaboradas a través de un potencial duelo colectivo? ¿Cómo podemos concebir el texto literario como una práctica cultural (Labanyi, 2010) que no se ofrezca como una forma estética de consolación?

Propongo entonces lo que se podría llamar una narrativa de duelo persistente: un narrativa que se resiste activamente a la sustitución, renunciando a la posibilidad de la consolación, donde la resistencia a la transacción metafórica mediante el sustituto constituye "el locus mismo en el que el duelo deviene una práctica afirmativa con consecuencias políticas" (Avelar, 1999: $203)^{13}$. Dicho de otro modo, una narrativa literaria sobre el pasado traumático no puede, ni debe, ofrecer la consolación por pérdidas pasadas y ni esperar otorgarle forma a aquello por su propia esencia carece de ella. Además, si según la primera economía freudiana del duelo el éxito del proceso de duelo se reducía a la transacción sustitutiva entonces la resistencia a su realización convierte el

${ }^{13}$ La traducción es mía. 
duelo en un proceso irrealizable (Avelar, 1999: 206) ${ }^{14}$. Aunque al nivel individual esto podría llevar a un proceso frenado o estancado, al nivel colectivo, esta persistente labor de duelo permitiría una elaboración de lo perdido que estuviera siempre abierta a través de la literatura postraumática y postmemorial, donde las pérdidas pasadas se reconocen como irreparables e irrecuperables, donde las ausencias heredadas se buscan sostener activamente en la obra literaria.

Entiendo las dos obras en cuestión como ejemplos de este duelo persistente. Pese a las diferencias que puede haber entre las dos, ambas comparten muchos rasgos, empezando por su carácter autoficticio en el que la figura del escritor/narrador reconstruye las historias de dos "personajes" borrados de la Historia. Sin embargo, ante el vacío dejado, el narrador se entrega a la suposición, bordeando la ausencia, haciendo que el vacío se instale como presencia central en la obra. Es en este sostenimiento de la pérdida que vemos al escritor/narrador como agente de memoria postraumático, quien construye no un testimonio directo de lo ocurrido en el pasado, ni tampoco una biografía exactamente, sino un testimonio de nuestra incapacidad de conocer esas pérdidas del todo y nuestro estado de inconsolables ante la ausencia.

\section{Elementos de ficción en Dora Bruder de Patrick Modiano}

Dora Bruder fue publicado en 1997 y constituye la última pieza de un largo proyecto emprendido varios años antes por el propio autor. Como explica el narrador, todo empezó tras descubrir un recorte de prensa en el año 1988 en un viejo ejemplar del periódico Paris-Soir del año 1941 en el que se anunciaba la desaparición de una joven judía de quince años. Conmovido por la noticia, Modiano publica en el año 1990 la novela Viaje de novios, inspirada en la historia de Dora Bruder.

Más tarde, gracias a su propia investigación y a los trabajos publicados por el historiador Serge Klarsfeld sobre las deportaciones de judíos franceses, Modiano consigue averiguar más sobre los hechos que llevaron a la detención y

\footnotetext{
${ }^{14}$ Esta noción de un duelo irrealizable, o un duelo imposible, tiene que ver con lo que Derrida denomina "la aporía del duelo": el duelo como labor tiene que fracasar (véase Derrida, 2001: 144).
} 
deportación a Auschwitz de Dora. En 1994, Modiano publica un artículo ("Avec Klarsfeld contre l'oubli") en el diario Libération en el que loa el trabajo de Klarsfeld y reflexiona sobre sus propios intentos de conmemorar esa historia a través de la ficción: "Y, de pronto, dudé de la literatura. Puesto que su principal motor es con frecuencia la memoria, me parecía que el único libro necesario que había que escribir era este memorial, tal como Serge Klarsfeld lo había hecho" (Modiano, 1994). Pese a sus dudas sobre el papel de la literatura, Modiano sigue adelante con su investigación. Con la ayuda de Klarsfeld, quien le proporciona más datos e incluso fotos de Dora, Modiano empieza a escribir lo que vendría a ser su novela, una obra en la que el narrador relata su búsqueda de cualquier información relacionada con la joven francesa ${ }^{15}$.

Se ha generado bastante debate en torno al género de Dora Bruder: En general, se ha caracterizado como una obra híbrida entre biografía, ficción y autobiografía (Suleiman, 2007), mientras otros la han caracterizado como "una investigación inacabada", "el relato de una investigación" o "un libro de conmemoración que trasciende los recuerdos personales" (Cooke, 2005: 288). Pese a las críticas a los que la han tildado de novela, no me decantaría exclusivamente por la calificación de investigación ${ }^{16}$. La obra de Modiano cuenta con elementos novelísticos e incluso alguna incursión cautelosa dentro del terreno de la ficción: aunque sí tiene como objetivo informar sobre el proceso de investigación y la historia de Dora, la obra está plagada de incógnitas que el propio narrador no deja de reconocer en ningún momento, cuya impotencia ante lo desconocido le provoca frustración al recorrer las mismas calles que la familia Bruder:

Dicen que los lugares conservan por lo menos cierta huella de las personas que los han habitado. Huella: marca en hueco o en relieve. Para Ernest, Cécile y Dora, yo diría: en hueco. Me embargaba una sensación de ausencia y de vacío cada vez que me encontraba en un lugar donde habían morado (Modiano, 2015:31) $)^{17}$.

\footnotetext{
${ }^{15}$ Sobre la correspondencia y colaboración entre Modiano y Klarsfeld, véase Morris (2006).

${ }^{16}$ Según Susan Suleiman, sería una distorsión significante llamar Dora Bruder una novela (2007: 346).

${ }^{17}$ A partir de aquí las referencias a esta edición se señalarán con las iniciales de la obra: $D B$.
} 
En las calles de París, tan cerca y a la vez tan lejos de Dora y su historia, las preguntas continuas del narrador, los "no lo sés" y frases como "me es imposible saber" llegan a formar el eje central de la narración: "Me preguntaba si existía algún documento, una pista que me pudiera proporcionar una respuesta. Me era imposible ir más allá de las meras suposiciones" (DB: 57-58). De las veintiséis secciones que forman el libro, once acaban con una pregunta, un vacío, una falta de información; diez de ellas empiezan así. Un tercio de ellas empieza con un hecho, dato o documento, pero estos siempre vienen seguidos por preguntas, posibles hipótesis, etc. (Cook, 2005: 293).

Hay momentos en los que el narrador se acerca ligeramente a la ficción, donde el texto se acaba de consolidar como narrativa de duelo, donde el recurso a la invención o a la imaginación no hace sino realzar la irrecuperabilidad total del pasado, situando la ausencia de Dora en el centro de la narración. Como sugiere el propio narrador al reflexionar sobre la inferencia y el papel del novelista, afirma que cree:

en el don de clarividencia de los novelistas [...]: el esfuerzo de la imaginación imprescindible en la profesión, la necesidad de fijar la atención en los pequeños detalles -y eso de manera obsesiva- para no perder el hilo y dejarse llevar por la pereza, toda esa tensión, esa gimnasia cerebral pueden sin duda provocar a la larga fugaces intuiciones 'concernientes a sucesos pasados y futuros', como dice el diccionario Larousse en la entrada "Clarividencia" (DB:51)

A veces el narrador se permite imaginar escenas o intuir los pensamientos de Dora: nos cuenta que Dora pasó el verano del 1940 en el internado del que más tarde se fugaría y que los domingos visitaba a sus padres. En una suerte de atisbo de los pensamientos de Dora, el narrador nos cuenta que para ella volver al internado a finales de verano "era como volver a la cárcel" ( $D B: 45)$. $\mathrm{O}$, por ejemplo, sabemos gracias a documentos que, tras su detención y la de su padre, Dora y Ernest, salieron de Drancy en un convoy dirección a Auschwitz, pero el narrador se atreve a imaginar que, entre los miles de detenidos, "entre el barullo, Dora encuentra a su padre, internado [en Drancy] desde marzo" de ese año ( $D B: 125)$. Más que invención total, estas inferencias producen lo que Dervila Cooke llama un "sutil efecto de ficción" (2005: 295), que sirve para establecer 
una conexión mental con Dora pese a la insistencia de que su verdad personal es inaccesible, tanto para el narrador como para nosotros los lectores.

Aunque parecería que el objetivo de Modiano es esclarecer todo lo posible relacionado con la vida, la desaparición y la subsiguiente deportación a Auschwitz de Dora, sabemos gracias al trabajo de Alan Morris que Modiano realizó una serie de correcciones y adiciones para la segunda edición de la obra (1999) en la que optó por no incluir toda la información de la que disponía. Esto, junto a la confusión producida por una narración no lineal y lo que es la mayor omisión por parte de Modiano (cualquier referencia a la colaboración del historiador Klarsfeld) demuestra que la técnica de Modiano no es la de un simple cronista o investigador, donde "el silencio, la ausencia, los vacíos, la información oculta o perdida y lo no contado son fundamentales" a la coherencia de la obra en sí (Morris, 2006: 283) ${ }^{18}$. Las correcciones hechas para la segunda edición constituyen un paso más en un proyecto continuo que no tiene fin concreto, ya que nunca podremos rellenar esa huella dejada en hueco. Igual que el duelo persistente, el proyecto de Modiano se concibe como una tarea irrealizable del todo, lo cual no supone un fracaso sino todo lo contrario: un proceso en un presente que permanece perpetuamente abierto.

\section{El papel de la ficción en El comprador de aniversarios}

Adolfo García Ortega, quien escribe el prólogo de la edición española de Dora Bruder en el que admite ser ávido lector del escritor francés, describe la obra de Modiano como "su mejor novela" e "incluso una de las mejores novelas aparecidas en los últimos años en Europa" ( $D B$ : 7). Además de sus comentarios laudatorios, el mismo García Ortega también reconoce y resalta los elementos ficticios y novelescos de la obra: "La iniciativa de Modiano de escribir sobre [Dora], de fabular sobre ella, ha permitido dotar de una cierta existencia a la Dora real. Esta es la fuerza de la ficción, que consolida como mito la verdad de la historia" (2005) ${ }^{19}$. Aunque la comparación de las dos novelas no va mucho más allá que unas meras menciones en reseñas periodísticas, creo que los

\footnotetext{
${ }^{18}$ La traducción es mía.

${ }^{19}$ La cursiva es mía.
} 
paralelismos que se pueden dibujar entre las dos novelas no son casuales $^{20}$. Ambas novelas comparten una misma reacción frente a los vacíos producidos por la catástrofe del Holocausto en la que el recurso a la ficción constituye la forma de lidiar con la irrecuperabilidad e irreparabilidad del pasado.

El narrador, convaleciente en un hospital en Frankfurt tras sufrir un accidente de coche que se produce camino a Auschwitz ("Una peregrinación tal vez pero nunca de turismo. ¿Cómo hacer turismo en Auschwitz?" (García Ortega: 11), ${ }^{21}$ cuenta cómo ha llegado a ese hospital y sus pensamientos durante el período de recuperación. Sus pensamientos giran en torno a las víctimas del Holocausto, en concreto a Hurbinek, el niño mencionado en La tregua de Primo Levi: "Hurbinek no era nadie, un hijo de la muerte, un hijo de Auschwitz. Parecía tener unos tres años, nadie sabía nada de él, no sabía hablar y no tenía nombre: aquel curioso nombre se lo habíamos dado nosotros" (2001: 263). Levi nos cuenta que este niño que "probablemente había nacido en Auschwitz" y que "nunca había visto un árbol" emitía unos sonidos o palabras que a los demás internados hacinados en la misma enfermería les eran imposibles de descifrar:

¿Qué palabra? No lo sabía, una palabra difícil, [...] algo parecido a 'mass-klo', 'matisklo'. [...] No siempre era exactamente igual, en realidad, pero era una palabra articulada con toda seguridad; o, mejor dicho, palabras articuladas ligeramente diferentes entre sí, variaciones experimentales en torno a un tema, a una raíz, tal vez a un nombre" (ibid.: 263-264).

Pese a la diversidad de nacionalidades que se encontraban allí en el campo, nos dice Levi que no consiguieron saber el significado de aquellas palabras.

Sobre ese sonido emitido por Hurbinek, Agamben escribe que "es el sonido que nos llega de la laguna, la no lengua que se habla a solas, [...]. Y es la naturaleza de eso no testimoniado, su no lengua, aquello sobre lo que es preciso interrogarse" (2000: 39). Es ante esa no lengua, esa laguna, que vemos al

\footnotetext{
20 "Esta segunda edición [de Dora Bruder] cuenta con un prólogo del narrador vallisoletano, poeta y editor Adolfo García Ortega. Y desde luego, un aire de Modiano tiene por ejemplo su novela El comprador de aniversarios (Herrero, 2010). El libro de Françoise Frenkel "lo ha traducido al castellano Adolfo García Ortega, también él, como Modiano, en sintonía con el personaje y su historia: es el autor de El comprador de aniversarios, premiada novela sobre la larga sombra de Auschwitz" (Cozarinsky, 2017).

${ }^{21}$ En adelante citaremos esta edición de El comprador de aniversarios con las inciciales ECA.
} 
narrador de El comprador de aniversarios interrogarse y reflexionar: ante el horror del sufrimiento y asesinato de un niño como Hurbinek a manos de la crueldad nazi, y consciente de su lugar en el tiempo y el espacio, alejado de las atrocidades de la Shoa, el narrador asume la ardua tarea de imaginar y de inventarse una vida posible para Hurbinek, ya que, como recuerda el propio narrador citando a Levi, "Nada queda de él: el testimonio de su existencia son estas palabras mías" (ECA: 13). Pese a que el narrador siente gratitud por las palabras de Levi, por haber evitado que el recuerdo de Hurbinek se borrase de la Historia, admite que no se puede saber nada sobre él. ¿Cómo sería Hurbinek hoy en día? ¿Quiénes eran sus padres? ¿De dónde venía? Consciente de las incógnitas, el narrador entiende que para contestar esas preguntas, solo nos queda la inferencia o la invención. Así el narrador marca el tono general desde las primeras páginas de la novela: "No se sabe, ni se sabrá nunca", "Su nombre nadie lo sabe", "Tal vez fuera así o tal vez no" (ECA: 17, 24, 113).

El narrador intercala las narraciones sobre su recuperación solitaria con ficciones sobre Hurbinek: de dónde venían sus padres, cómo es que llegaron al campo, qué familia tenía. Dice que no pretende contar una historia sobre las víctimas del Holocausto, la solución final y la eficacia mecánica del genocidio, que solo quiere hablar de Hurbinek, porque es "el más atroz símbolo del silencio que jamás haya podido crear la Historia"; un silencio al que responde con la ficción: "Quiero que Hurbinek exista. Que exista otra vez. Que exista por más tiempo. Que dure su existencia. Que tenga una vida inventada, posible. Fabricada por mí. [...] Quiero regalarle, comprarle años, celebraciones de cumpleaños, si eso no fuese una quimera" (ECA: 10, 87).

En el cuarto capítulo, el narrador relata la posible historia de los padres de Hurbinek a través de secciones que no se leen cronológicamente, pero que empiezan con los subapartados de "X años antes/después" de la muerte de Hurbinek, dejando claro que las vidas de estas personas giran en torno a Hurbinek. En el séptimo capítulo, dividido en varias secciones, cada una titulada con el nombre de un hombre que podía haber sido Hurbinek, desarrolla posibles vidas para este, como si hubiese sobrevivido. Las posibles vidas inventadas por el narrador corresponden a vidas ficticias, cosa que sabemos los lectores por 
admisión propia del narrador. En cada uno de los ejemplos, el narrador construye una posible historia de cómo podía haber llegado el pequeño Hurbinek a sobrevivir, a ser adoptado o a encontrar hogar en algún lugar, años después; el narrador afirma que seguramente el propio Hurbinek ni siquiera sería consciente de su propio pasado. Este capítulo está plagado de adverbios y frases que invocan la duda, la incertidumbre, la posibilidad: "Tal vez la vida de Hurbinek sea de verdad la vida de ese individuo, de ese tal Farin, de nacionalidad rusa; una vida vivida de manera interpuesta, decidida por mí, creador de su futuro. ¿Por qué no? ¿Y por qué no más vidas? ¿Por qué no otras vidas posibles?" (ECA: 117).

El recurso a la invención no se limita únicamente al origen y las posibles vidas de Hurbinek de haber sobrevivido a Auschwitz. El narrador también nos relata episodios de la vida de Primo Levi y Henek, el joven de quince años (cuyo nombre verdadero era Belo König), que se dedica a cuidar de Hurbinek, según el testimonio de Levi. Una vez que el narrador nos sitúa claramente en el territorio de la invención, este procede a narrar escenas e inventar detalles sobre personas que sí existieron, convirtiéndolos en ficción: "Sigo a Primo Levi con el pensamiento" (ECA: 46). Por ejemplo, el narrador recrea el día en el que Levi se suicida, narrando lo que hacía, lo que sentía, observaciones e inferencias que van mucho más allá de lo que podemos saber por datos bibliográficos o cualquier información contrastable sobre la vida de Levi:

Primo Levi anduvo a tientas por el pasillo de su casa, donde vivía con su mujer Lucia. [...] Estaba muy deprimido, más que nunca tal vez, y le preocupaba su cáncer de próstata. Ya no amaba la vida, y se preguntaba de dónde sacaría argumentos para amarla nuevamente (ECA: 42-43)

Más tarde relata que en un paseo en un callejón, el mismo día de su muerte, Levi se da cuenta de que ha "olvidado el rostro de su madre cuando era joven. Era para él la premonición que antecede a la verdadera y definitiva muerte."(ECA: 44). O, en el caso de Henek/König, el narrador nos cuenta que sobrevive a Auschwitz y vuelve a su Hungría natal para luego alistarse en el ejército, donde llega "pronto al rango de capitán de las fuerzas que se enfrentaron a los soviéticos en 1956 en las calles de Budapest" (ECA: 78). 
Imaginar lo que podía haber sido de Hurbinek si hubiese sobrevivido tal vez no supone una "infracción al orden", pero para Hackl suponemos que la invención y descripción del último día de vida de Levi o lo que le pasó después a Henek sí que constituiría una alteración e invención innecesarias de la Historia.

La línea entre realidad e invención se vuelve menos clara todavía cuando la ficción desborda los límites de la narración e invade los paratextos. Después del último capítulo, el autor incluye una dedicatoria en la que dedica la novela a la memoria de las personas que aparecen allí nombradas. Todos, menos Belo König (Henek), son personajes inventados: los que compartieron los últimos días de Hurbinek, sus padres, los que tuvieron algún contacto con él durante su tiempo en el campo y luego Ari Pawlicka, el nombre "real" que el narrador inventa para Hurbinek. Como lectores, dudamos al leer estos nombres en la dedicatoria, pero pronto nos damos cuenta de que, primero, se trata de los personajes de la trama de la novela y, segundo, que ante la imposibilidad de saber tantos otros nombres de los que perecieron en el anonimato, a García Ortega no le queda más remedio que dedicar su novela a sus personajes inventados, quienes convivieron en sus historias y vidas creadas por el propio autor con aquellas personas reales y anónimas que no volvieron: "Esta novela está dedicada a la memoria de Schlomo Buczko, Belo König, Rubem Yetzev [...] que con otros nombres existieron" (ECA: 245).

A pesar de todas estas invenciones, la novela no sufre una pérdida de realismo. Luís María Romeu Guallart comenta este uso de la imaginación por parte del narrador en la novela de García Ortega: el autor "demostrará que no por trabajar desde la imaginación su novela es menos realista que las que tratan de servirse exclusivamente de la documentación" (2010: 169). García Ortega rompe con cualquier noción de ambigüedad a través de la admisión por parte del narrador de que no puede saber todos los detalles sobre lo que le pasó a Hurbinek o a los otros, construyendo un relato que es ficticio pero verdad a la vez, convirtiendo las "lagunas del conocimiento" sobre Hurbinek en símbolos a través de la imaginación donde el resultado final es una ficción que es "una nueva forma de conocimiento" (ídem). Acerca de El comprador de aniversarios, Muñoz Molina escribe del poder de la ficción: "Quizás necesitemos algo más, un grado 
de identificación -no de escuchar a los otros sino de acercarnos más a ellos, de ponernos de algún modo en su lugar- que sólo puede ofrecernos, paradójicamente, el arte de la ficción" (2003: 76).

Estoy de acuerdo con lo que escribe Muñoz Molina, que ante la ausencia de la tragedia del Holocausto, ante ese "evento sin testigo", hoy en día, desde el presente, lo único que nos queda para reaccionar ante esa ausencia es la ficción. Pero matizaríamos sus palabras: una identificación con Hurbinek, ponernos en su lugar, no es posible y no debería serlo. Con quien sí nos podemos identificar por medio de la novela de García Ortega es con el narrador: podemos ponernos en su lugar, el lugar de alguien temporal y espacialmente distanciado de Auschwitz y, sin embargo, tocado, herido y afectado por la violencia terrible del siglo XX. Ese es también nuestro lugar como lectores: como lo que nos relata el narrador al principio de la novela "Auschwitz está demasiado cerca" (ECA: 9). Nos concierne, nos incumbe. $Y$, sin embargo, somos como el narrador, quien "iba a Auschwitz, pero ya no" (ECA: 243).

A diferencia de muchas de las novelas publicadas durante el mismo período en España sobre la Guerra Civil, que combaten la falta de memoria a través de una ficción cargada de investigación historiográfica para arrojar luz sobre lo desconocido, El comprador de aniversarios "traza línea de lo desconocido y no proyecta sobre esa frontera una luz ilusoria, sino que nos vuelve conscientes de la extensión sin límite de lo que está más allá" (Muñoz Molina, 2003: 76-77).

En su libro The Holocaust and the Postmodern, Robert Eaglestone distingue entre dos tipos de verdad que pueden operar a la vez: existen "truth as explanation, corresponding to evidence and states of affairs and truth as in some way revealing of ourselves, of "who and how we are»" (7). El comprador de aniversarios constituiría sobre todo un ejercicio en esta segunda verdad, una que es capaz de revelarnos "quiénes somos y cómo estamos" ante una catástrofe como el Holocausto. A la observación de Lyotard de que el Holocausto nos dejó sin los instrumentos necesarios para siquiera medir los daños, Geoffrey Hartman responde que el terremoto no se pudo medir, pero hoy las réplicas son mensurables (en Eaglestone 2004: 2). La novela de García Ortega, un testimonio 
de "quiénes somos y cómo estamos" ante el pasado, supone un ejercicio literario en el que la ficción se convierte en una herramienta para medir los efectos que aún perduran en el presente.

\section{Conclusiones}

Hemos propuesto aquí una lectura de El comprador de aniversarios como una narrativa de duelo cuya estética y modo de acercarse al pasado vienen influenciados por la novela de Modiano. Podemos destacar la novela de García Ortega por su uso de ficción: si en muchas novelas del boom de la memoria, la ficción sirve como medio para exhumar episodios, víctimas, historias no conocidas $\mathrm{u}$ olvidadas y así actualizar la memoria colectiva sobre el pasado violento en España, en la obra de García Ortega, el narrador revela su intención de usar la ficción, la invención y la suposición para especular sobre lo que podía haber pasado o no, haciendo hincapié en la imposibilidad de saber. Ante la ausencia de la tragedia del Holocausto hoy en día, desde el presente, la ficción nos proporciona un modo de posicionarnos.

Pese a las diferencias entre las dos obras (Modiano, francés y de origen judío; García Ortega, español, sin vínculo directo con el Holocausto), los dos autores escriben desde un imperativo ético de acercarnos, de modo posible, a las pérdidas y ausencias provocadas por la tragedia del Holocausto. En El comprador de aniversarios el narrador cita unas palabras del escritor y víctima del Holocausto Jean Améry, quien "escribió en uno de sus libros «La palabra cesa en cualquier lugar donde una realidad se impone como forma totalitaria. » [...] La palabra que halló Améry tal vez fue la misma que pronunció Hurbinek: el desesperado intento por decir el silencio" (ECA: 148-149).

En el caso de las dos novelas, los narradores no son supervivientes del Holocausto: forman parte de "los que vienen después". No pueden dar cuenta de lo que no han vivido, pero sí que pueden testimoniar desde su propia posición alejada del momento de la catástrofe. Reflexionar, inferir e inventar ante la ausencia dejada por la tragedia constituye un modo de "ceder su lugar a una no lengua, mostrar la imposibilidad de testimoniar" (Agambden, 2000: 39). Estas novelas se esfuerzan por conmemorar las historias de Dora Bruder y Hurbinek y 
por no dejar que sus memorias caigan en el olvido. Como narrativas postraumáticas de duelo persistente, donde hay lagunas sobre el pasado de estas personas, resisten activamente la consolación, optando en su lugar, por convertir su narrativa en una expresión literaria de esa ausencia, un intento por decir el silencio.

\section{BiBLIOGRAFÍA}

Agamben, Giorgio (2000 [1999]): Lo que queda de Auschwitz. Valencia: Pretextos.

AvELAR, Idelber (1999). "Restitution and Mourning in Latin American Postdictatorship". Boundary 2. Vol. 26, N.ㅇ 3, pp. 201-224.

BAER, Alejandro (2015). "Ghosts of the Holocaust in Franco's mass graves: Cosmopolitan memories and the politics of 'never again'". Memory $\begin{array}{lllll}\text { Studies. } & \text { Vol. } & \text { 8. } & 0 & \end{array}$ http://dx.doi.org/10.1177/1750698014568247

BECERRA MAYOR, David (2015). La guerra civil como moda literaria. Madrid: Clavel Intelectual.

BRISLEY, Lucy (2013). "The Will to Remember: Problematizing the Ethico-Politics of Mourning and Melancholia". The International Journal of Civic, Political, and Community Studies, Vol. 10, pp. 61-72.

CoOKE, Dervila (2005). Present Pasts. Patrick Modiano's (Auto)biographical Fictions. New York: Rodopi.

COZARINKSY, Edgardo (2017). "La audacia de dos espírtus apátridas”, Clarín, 2303-2017, en https://www.clarin.com/revista-n/literatura/audacia-espiritusapatridas_0_ BJ8gBl1he.amp.html [Fecha de consulta: 24 de abril de 2017].

Clewell, Tammy (2009). Mourning, Modernism, Postmodernism. New York: Palgrave MACMILLAN.

DERRIDA, Jacques (2001). The Work of Mourning. Chicago: The University of Chicago Press.

Eaglestone, Robert (2004). The Holocaust and the Postmodern. New York: Oxford University Press.

ENG, David L. y HAN, Shinhee. "A Dialogue on Racial Melancholia." En ENG, David L. y KaZANJIAN, David (eds), Loss: The Politics of Mourning. Berkeley: University of California Press, pp. 343-371.

FABER, Sebastiaan (2012). "Raising the Specter of 'Argentinization': The Temptation of Spanish Excepctionalism". Hispanic Issues Online. Vol. 11, 117-136, en https://conservancy.umn.edu/handle/11299/184377 [Fecha de consulta: 28 de abril de 2017].

FABER, Sebastiaan. (2005). "The Price of Peace: Historical Memory in PostFranco Spain, a Review-Article”. Revista Hispánica Moderna. Vol. 58, N. 1-2, pp. 205-219.

FELMAN, Shoshana y LAUB, Dori (1992). Testimony. Crises of Witnessing in Literature, Psychoanalysis, and History. New York: Routledge. 
GARCíA ORTEGA, Adolfo [2002] (2008). El comprador de aniversarios. Barcelona: Seix Barral.

García Ortega, Adolfo (2005). “¿La sumisión como utopía?”, en http://www.adolfogarciaortega.com/galaxia/galaxia_sumision.html [Fecha de consulta: 23 de abril de 2017].

GATTI, Gabriel (2012). Identidades desaparecidas: Peleas por el sentido en el mundo de la desaparición forzada. Buenos Aires: Prometeo Libros.

HACKL, Erich (2001b). "'El caso Sefarad' La responsabilidad de escribir sobre personas reales". Lateral. N.. 81, en http://circulolateral.com/revista/ articulos/081 sefarad.htm, [Fecha de consulta: 19/02/2016].

HACKL, Erich (2001a). "EI caso Sefarad' Industrias y errores del santo de su señora". Lateral. N.. 78, en http://circulolateral.com/tema/078ehackl.htm, [Fecha de consulta: 19/02/2016].

HANSEN, Hans Lauge (2012). "Formas de la novela histórica actual". En La memoria novelada. Bern: Peter Land. 83-103.

HeRRERO, Fermín (2010). "En ésas andamos", El norte de Castilla, 23-01-2010, en http://www.elnortedecastilla.es/20100123/cultura/esas-andamos20100123.html [Fecha de consulta: 24 de abril de 2017].

LABANYI, Jo (2010). "Doing Things: Emotion, Affect, and Materiality". Journal of Spanish Cultural Studies. Vol. 11, N. 3-4, pp. 223-233.

LEVI, Primo [1963] (2001). Trilología de Auschwitz. Barcelona: El Aleph Editores. MARTínEZ RUBIO, José (2015). La formas de la verdad. Investigación, docuficción y memoria en la novela hispánica. Madrid: Anthropos Editorial.

MODIANO, Patrick [1997] (2015). Dora Bruder. Barcelona: Seix Barral.

MorRIS, Alan (2006). "'Avec Klarsfeld contre l'oubli' Patrick Modiano's Dora Bruder". Journal of European Studies. Vol. 36, N. 3, pp. 269-293. http://dx.doi.org/10.1177/0047244106069046

MuÑOZ MoLINA, Antonio (2003). "La novela del desaparecido". Letra Internacional. Invierno. 76-77.

NUCKOLS, Anthony (2016). "La novela de duelo frente a la novela de memoria histórica". Caracol. Vol. 11 (enero-junio), pp. 210-243. http://dx.doi.org/10.11606/issn.2317-9651.v0i11p210-243

ROMEU GualLaRT, Luís María (2010). 'Yo iba a Auschwitz pero ya no.' El comprador de aniversarios de Adolfo García Ortega y las posibilidades de acercarnos a la Historia desde la (meta)ficción", Confluenze, Vol. 1, N.ำ pp. 165-184.

S.A. (2006). "Entrevista con Benjamín Prado". El País, en http://cultura.elpais.com/cultura/2006/05/17/actualidad/1147878000_114 7880084.html [Fecha de consulta: 19/04/2016].

SUlEIMAN, Susan (2007). "'Oneself as Another': Identification and Mourning in Patrick Modiano's Dora Bruder". Studies in 20th \& 21st Century Literature. Vol. 31, No. 2, pp. 325-350. https://doi.org/10.4148/2334-4415.1656

VICE, Sue (2000). Holocaust Fiction. New York: Routledge.

WHITEHEAD, Anne (2004). Trauma Fiction. Edinburgh: Edinburgh University Press.

Fecha de recepción: 10 de mayo de 2017

Fecha de aceptación: 8 de septiembre de 2017 